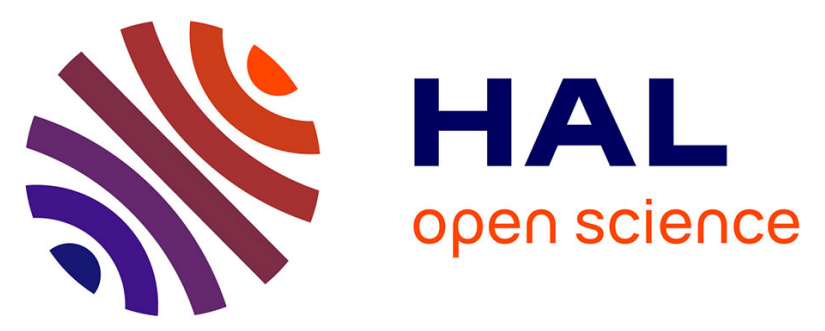

\title{
Active Learning session based on Didactical Engineering framework for conceptual change in students' equilibrium and stability understanding
}

Michaël Canu, Mauricio Duque, C. de Hosson

\section{- To cite this version:}

Michaël Canu, Mauricio Duque, C. de Hosson. Active Learning session based on Didactical Engineering framework for conceptual change in students' equilibrium and stability understanding. European Journal of Engineering Education, 2016, 42 (1), pp.32 - 44. 10.1080/03043797.2016.1190689 . hal01637693

HAL Id: hal-01637693

https://hal-univ-paris.archives-ouvertes.fr/hal-01637693

Submitted on 11 Jan 2018

HAL is a multi-disciplinary open access archive for the deposit and dissemination of scientific research documents, whether they are published or not. The documents may come from teaching and research institutions in France or abroad, or from public or private research centers.
L'archive ouverte pluridisciplinaire HAL, est destinée au dépôt et à la diffusion de documents scientifiques de niveau recherche, publiés ou non, émanant des établissements d'enseignement et de recherche français ou étrangers, des laboratoires publics ou privés. 


\section{Active Learning session based on Didactical Engineering framework for conceptual change in students' equilibrium and...}

Article in European Journal of Engineering Education · January 2017

DOI: $10.1080 / 03043797.2016 .1190689$

CITATIONS

0

3 authors:

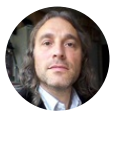

Michaël Canu

El Bosque University

15 PUBLICATIONS 38 CITATIONS

SEE PROFILE

Mauricio Duque

Los Andes University (Colombia)

39 PUBLICATIONS 94 CITATIONS

SEE PROFILE
READS

84

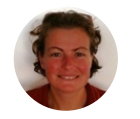

Cécile De Hosson

Paris Diderot University

55 PUBLICATIONS 143 CITATIONS

SEE PROFILE

Some of the authors of this publication are also working on these related projects: 
Accepted for publication in European Journal of Engineering Education, 2016 :

http://dx.doi.org/10.1080/03043797.2016.1190689

Active learning session based on Didactical Engineering framework for conceptual change in students' equilibrium and stability understanding

Canu, Michael*; Duque, Mauricio*; de Hosson, Cécile**

*GIEE STEM+B, Universidad de los Andes, Bogotá, Colombia; **LDAR (EA4434), université Paris Diderot Paris 7, Paris, France

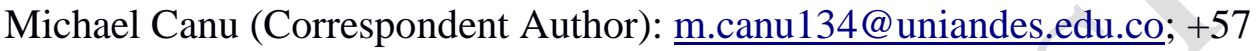

3187543421; Edificio Mario Laserna Cra 1 Este No 19A - 40 Bogotá (Colombia).

Mauricio Duque: maduque@ uniandes.edu.co; Edificio Mario Laserna Cra 1 Este No 19A - 40 Bogotá (Colombia).

Cécile de Hosson: cecile.dehosson@univ-paris-diderot.fr; Université Paris Diderot, Bâtiment Condorcet, UFR de Physique, Case Courrier 7086, 75205 Paris Cedex 13 
Accepted for publication in European Journal of Engineering Education, 2016 : http://dx.doi.org/10.1080/03043797.2016.1190689

\title{
Active learning session based on Didactical Engineering framework for conceptual change in students' equilibrium and stability understanding
}

\author{
Engineering students on control courses lack a deep understanding of equilibrium \\ and stability that are crucial concepts in this discipline. Several studies have \\ shown that students find it difficult to understand simple familiar or academic \\ static equilibrium cases as well as dynamics ones from mechanics even if they \\ know the discipline's criteria and formulae. Our aim is to study the impact of a \\ specific and innovative classroom session, containing well-chosen situations that \\ address students' misconceptions. We propose an example of Active Learning \\ experiment based either on the Didactical Engineering methodology and the \\ Conceptual Fields Theory that aims at promoting a conceptual change in \\ students. The chosen methodology allows, at the same time, a proper design of \\ the student learning activities, an accurate monitoring of the students' rational use \\ during the tasks and provides an internal tool for the evaluation of the session's \\ efficiency. Although the expected starting conceptual change was detected, it \\ would require another activity in order to be reinforced.
}

Keywords: Didactical Engineering; Conceptual Change; Conceptual Fields; Equilibrium; Stability.

\section{Introduction}

Equilibrium is a scientific concept that appears in control theory as well as in mechanics, electricity or many others disciplines in natural or social sciences. In fact, equilibrium is a cross-cutting concept involved in all areas that use a systemic approach and that deal with complex systems like engineering. For this reason, it is included in all curricula across the world at many levels from primary school (in France for example) to university. The importance of this concept was pointed out once again by the National Research Council in this "Framework for K-12 science education" (2012) 
Accepted for publication in European Journal of Engineering Education, 2016 : http://dx.doi.org/10.1080/03043797.2016.1190689

which is the base of the "Next Generation Science Standard" in the United States: "Constancy, often in the midst of change, is also the subject of intense study in science" (American Association for the Advancement of Science, 1993). This constancy is exactly what equilibrium means: a particular stationary state.

As mentioned above, this study is focused on the part of engineering education that deals with the control of dynamic systems. In this discipline, the equilibrium concept is generally presented in mathematical terms: an equation's fixed point ${ }^{\mathrm{i}}$, and leans on examples from mechanical systems. That is why we focus on this area but it is clear that the global aim of this sequence is to change the student's equilibrium understanding in all the disciplines in which it is used (chemistry, electricity, etc.).

In control courses, one observes a lack of a deep understanding of equilibrium and stability among the engineering students. However, throughout their syllabus, equilibrium and stability are approached in different ways, and at different academic stages: at early stages in essentially static ways, in mechanics for example, and later, by dynamical analysis, in control courses. In fact, there is little clarification regarding the differences between those ways and how they are linked. We assume that it is a major source of confusion and misunderstanding (misconceptions) for engineering students. This confusion is also strengthened by the use of those words in everyday-life with a meaning that does not coincide with their scientific meaning. Several studies have shown that students encounter difficulties in understanding simple familiar or academic static equilibrium cases from mechanics (Newcomer et al., 2008; Ortiz et al., 2005; Palmer, 2001; Flores-García, 2010; Gunstone, 1981) and some others show that the understanding of equilibrium and stability is strongly disturbed in case of moving reference frames (Tamayo et al., 2012; Canu et al. 2014) even if students know the 
Accepted for publication in European Journal of Engineering Education, 2016 : http://dx.doi.org/10.1080/03043797.2016.1190689

discipline's criteria and formulae. In fact, few of the students' difficulties seem to be linked directly to a lack of theoretical knowledge concerning the mechanical concepts of equilibrium and stability, but instead from the results of inappropriate reasoning. In fact, while many classical engineering control courses are mainly focused on declarative and procedural knowledge (Shavelson et al., 2005) they cannot improve students' understanding of equilibrium and stability throughout various situations because this implies strategic skills or reasoning. Our research question is therefore: is it possible to improve this kind of equilibrium and stability understanding in students and how?

\section{Overview of research}

\section{Equilibrium and stability}

Many studies have focused on the understanding of equilibrium concept beyond the mere knowledge of criteria, and most of them deal with equilibrium while almost none are concerned with stability (which is probably considered to be a separate concept). Much research has been devoted to investigating students' difficulties in understanding general physics concepts, including equilibrium, in order to identify alternative modes of reasoning. Gunstone (1987), for example, observed that many students have trouble understanding various concepts in mechanics, especially equilibrium in static pulley/mass systems. He concluded that many students could actually be reasoning in ways that are quite different from those taught in classrooms. For example, in the pulley/mass system, after pulling down one of the mass, many students (44\%) predicted the masses (equal masses on each side of the pulley) would return to their initial positions (same level) involving the use of equilibrium. 
Accepted for publication in European Journal of Engineering Education, 2016 : http://dx.doi.org/10.1080/03043797.2016.1190689

Albanese et al. (1998) examined this issue from a historical point of view by taking into account the influence of real-life (i.e. every-day), non-academic situations on the construction of students' reasoning, otherwise known as spontaneous reasoning or common-sense reasoning (Viennot, 1979). They brought to light certain energy and dissipative aspects that distinguish academic situations from those of everyday life and possibly influence or even account for some of the difficulties in understanding the studied phenomena.

Some studies have dealt with the equilibrium concept indirectly in their investigations on the mechanisms that could lead to alternative reasoning about general physics situations and therefore the above mentioned difficulties. One example is the study by Pozo et al. (1992), who organized and classified students' alternative reasoning in the form of mini-theories. In this study, the students were asked to reflect on simple static situations (e.g. a book on a table, on a ball, on a spring, etc.) and the authors were able to identify the strong role of context and the apparent inconsistency of the students' reasoning facing with situations involving the very same physical principle as the action/reaction principle related to static equilibrium situations.

Other investigations have been specifically focused on the understanding of equilibrium. Some were carried out at the child's psycho-developmental level in line with the work of Piaget, such as Siegler and Chen (2002), Bonawitz, Lim, and Schulz (2007), and others at the undergraduate level, for example the study by Newcomer and Steif (2008), in which students were asked to express their views on the equilibrium of static systems of rope-connected beams, that by Ortiz, Heron, and Shaffer (2005) involving prototypical static balance systems, or the work of Flores-García et al. (2010) concerning mixed static pulley/mass or pulley/spring systems. 
Accepted for publication in European Journal of Engineering Education, 2016 : http://dx.doi.org/10.1080/03043797.2016.1190689

Setting aside the study carried out on children — which nevertheless reveals some very interesting aspects pertaining to the basic reasoning about the moments of forces or distance/mass compensation — it is once again apparent that students' conception about a particular system is highly dependent on the context and some visual aspects. For example, it seems that most students believe that the horizontality of a fulcrum is the sole equilibrium criterion for systems that look like a balance scale (Ortiz et al., 2005), and hold the same belief about the identical height of two masses suspended on either side of a pulley (Gunstone, 1987).

As for the application of textbook criteria, rules or methods such as the sum of forces and moments, these studies suggest that students have difficulty in applying all of them together (Ortiz et al., 2005, Newcomer \& Steif, 2008) (i.e., they may check for equilibrium by using the sum of forces or the sum of moments, but not both) or fail to include all the forces in their reasoning, with some internal forces being overlooked (Newcomer \& Steif, 2008).

To date, only static equilibrium (within the field of mechanics) has been dealt with in the literature and its link with stability has yet to be considered. On the one hand, those concepts are scientifically linked even if it is possible to separate them (i.e. to speak of equilibrium without speaking of stability as it is the case in almost undergraduate levels). On the other hand, Canu et al. (2014) found that in students' minds, those concepts are mixed up and lead to assimilation and priority phenomena which can be revealed in dynamic system cases. So, we claim that studying the link between those two concepts is an appropriate way to access student's reasoning.

\section{Conceptual Fields Theory and conceptual change}

In light of the above we propose a conception - or reasoning - typology about the equilibrium/stability concepts within the French constructivist framework of the 
Accepted for publication in European Journal of Engineering Education, 2016 : http://dx.doi.org/10.1080/03043797.2016.1190689

Conceptual Fields Theory (Vergnaud, 2009). This theory is a developmental one and, as said by Vergnaud himself, she

"[...] has two purposes: (1) to describe and analyse the progressive complexity, on a long - and medium-term basis, of the mathematical competences that students develop inside and outside school, and (2) to establish better connections between the operational form of knowledge, which consists on action in the physical and social world, and the predicative form of knowledge, which consists on the linguistic and symbolic expressions of this knowledge".

Vergnaud uses the concept of schemes that are the roots of cognitive development as many psychologists - like Piaget - defined them. The function of a scheme is "both to describe ordinary ways of doing, for situations already mastered, and to give hints on how to tackle new situations" (Vergnaud, 2009, p. 88). They are adaptable - or we could say dynamic - resources that allow the assimilation of new situations by accommodating to them. For that purpose, they must contain ready-made rules, tricks and procedures that have been shaped by already mastered situations - operational invariants, namely concepts-in-action and theorems-in-action - as well as a process of adaptation, a computational aspect that generates goals, subgoals and rules, as well as properties and relationships that are not observable (inferences). Schematically, each situation provides common elements from which the subject is going to construct operational invariants. From these invariants, the subject can analyse a new situation, acts and extracts possibly new operational invariants, and so on: this two-way construction is called relational calculus.

So, this theory provided a framework in which we are able to seek influences from experiences - everyday one as well as academic one - in students' behaviour or reasoning in front of some equilibrium situations. Those reasoning or conceptions may 
Accepted for publication in European Journal of Engineering Education, 2016 : http://dx.doi.org/10.1080/03043797.2016.1190689

constitute a scheme made up from concepts-in-action and action rules. In fact, Canu \& Duque (2014) identified three main reasoning - i.e. conceptions - about equilibrium, named: "equilibrium-immobility", "equilibrium-stable" and "equilibrium-unstable" as represented in figure 1 (Canu, 2014) which gives a representation of the scheme in the Conceptual Fields Theory framework. In this diagram, the top plane represents the operational invariants space and the lower plane represents the action rules plane. Both are linked by relational calculus.

[Figure 1. near here]

They can be seen as three conceptions about this concept. As many conceptions, these ones are operational in some situations but the generalisation of the correspondent action rule, for example in the sense of a binary opposition, may lead to application errors. For example, the "equilibrium-immobility" reasoning works in the case of a book at rest on a table (which is an equilibrium situation) but many students use the opposite $^{\mathrm{ii}}$ of this same rule to justify the fact that if an object is moving, this implies its non-equilibrium state (which is false in general while objects in a translation movement at a constant speed are in mechanical equilibrium).

The important thing here is that this set of conceptions does not constitute one single conception of equilibrium in students' mind - but it is one single scheme - but three, which are not clearly linked. It seems that this aspect is responsible for the apparent incoherence of the students' reasoning in equilibrium situations. In fact, depending on the studied situation, students will use only one of these scheme aspects at the same time. This point of view is close to the diSessas's or Minstrell's one: it is a fragmented view of student's conceptions. Those three misconceptions, showed in Canu \& Duque 
Accepted for publication in European Journal of Engineering Education, 2016 : http://dx.doi.org/10.1080/03043797.2016.1190689

(2014) [p. 296], play the same role as the elements shown in diSessas et al. (2004) [p. 850]. In fact, they might represent Minstrell's facets (Minstrell, 1992) or some sets of diSessa's p-prims (diSessa, 1993).

Moreover, from this Conceptual Fields Theory's point of view, the lack of a link between those conceptions in students' mind - said that is, the structure of the schemes - is both the result and the cause of the lack of confrontation with rich ${ }^{1}$ equilibrium situations. Thus, the theory directly provides an idea for changing this conceptual structure: students must be exposed to a problem-situation that contains a set of specific equilibrium situations, and which are representative of the three identified reasoning. This could drive students to link or merge all their previous equilibrium conceptions into a broader one, closer to the scientific equilibrium concept: this reorganisation is what we call conceptual change here. Figure 2 represents the final state of the scheme in the chosen representation of Theory of Conceptual Fields. The reorganisation is symbolised by the inclusion of the three mechanical equilibrium types (indifferent, stable and unstable) into the equilibrium concept (conceptual invariants plane). Because of the strong interdependence between the action rules and the conceptual invariants, the action rules will be merged too, in a behavioural way of thinking (like "What is the system behaviour from the initial equilibrium state faced with a perturbation?".

[Figure 2. near here.]

Thus, our research question could be refined in this way: Is it possible to change engineering students' conception (their equilibrium concept understanding) by confronting them with appropriate situations? This study aims at designing and testing a classroom sequence that promotes this kind of conceptual change in engineering 
Accepted for publication in European Journal of Engineering Education, 2016 : http://dx.doi.org/10.1080/03043797.2016.1190689

students' mind in order to bring them to understand all equilibrium situations in a more coherent way. As it is a constructivist point of view, this aim cannot be reached without the use of a student-centered teaching approach, namely an Active Learning approach. That is why in order to design the expected classroom sequence we decided to use the Didactical Engineering (Artigue, 1994) methodology.

\section{Didactic Engineering framework and Active Learning}

The design and the assessment of the sequence are in fact embedded in this methodology. As Artigue said, "Didactical engineering is the design and experimentation of teaching sequences, adopting an internal mode of validation based on the comparison between a priori and a posteriori analysis within the framework of the Theory of Didactical Situations (Brousseau, 1997)". It is, with some precautions discussed at the end of this article, at the same time a research methodology and a methodology to develop teaching products.

In fact, the Active Learning core of our work resides mainly in this methodological framework. As said Prince (2004) "Active learning is generally defined as any instructional method that engages students in the learning process. In short, active learning requires students to do meaningful learning activities and think about what they are doing ${ }^{\mathrm{iii}}$. That is exactly the basement of the Brousseau's Theory of Didactical Situation that underpin the Didactical Engineering methodology. As Brousseau said, "Teaching consists exactly in bringing about expected learnings in students by putting them in appropriate situations in which they will respond spontaneously by some adaptations" (Brousseau, 1988, p. 324). The (learning) situations to which he refers are real active learning situations because they cause students adaptations, namely constructions of knowledge. Moreover, in the Didactical Engineering these adaptations must lead to students' observable behaviours, in a word, actions. Some authors like Chi 
Accepted for publication in European Journal of Engineering Education, 2016 : http://dx.doi.org/10.1080/03043797.2016.1190689

(2009) call this kind of activities "constructive learning" and it is considered that this kind of activity implies more than simply "doing something" (hands-on). As Bonwell \& Eison wrote in their report about what Active Learning is (see endnote 3), students "must read, write, discuss, or be engaged in solving problems", namely be involved, which not necessarily implies hands-on or group activities. However, the proposed sequence includes some group activities in order to promote socio-cognitive conflicts (see the description below). All of these aspects allows us to match 5 of the 6 hints proposed by Vos \& de Graaff (2007) to raise the effectiveness of an active learning activity (the learning objective is not open as we want students overcome a specific conceptual difficulty).

\section{Methodology}

The Didactical Engineering includes four steps:

1. A preliminary analysis investigating the epistemological, cognitive and institutional conditions and constraints;

2. A design and a priori analysis with particular attention paid to the identification and selection of values for the didactic variables and anticipation of their potential effect on the "students-milieu $u^{i v " ~ i n t e r a c t i o n ; ~}$

3. An experimentation;

4. And a posteriori analysis and validation of the hypotheses underlying the design

The major part of the first step is included in the previous sections of this article, except the institutional and historical issues we cannot detail here (for more details, see Canu, 2015). As said before, the core of this methodology is the second step which completely relies on the interaction between students and the learning environment that Brousseau called the milieu (Brousseau, 1988, p. 321). This interaction could be seen as a process 
Accepted for publication in European Journal of Engineering Education, 2016 : http://dx.doi.org/10.1080/03043797.2016.1190689

of "equilibration" (Piaget, 1950) from which we assume it is possible to drive the students' behaviour by the management of a given milieu. The main idea here is to hypothesize some specific links between the construction of knowledge and the behaviour of students in a particular situation (which is a part of the milieu). Thus, by managing some didactical variables of the situation one can foster a student's particular behaviour which then implies the construction of the desire knowledge. In fact, we can only "see" the behaviour of students, and not directly the construction of the desired knowledge because it is a internal, personal, cognitive process; that's why the a priori analysis should provide some elements that link the students' behaviour and the knowledge construction. Those elements are specific hypothesis, called didactical engineering hypothesis here ("DEH" in the following). Finally, the students' behaviour in the situation is attested by way of some hypothesis indicators ("DEHI") which are the observable elements we are going to seek in the activity records (videos, audios, questionnaires, etc.).

\section{The sequence design}

As shown in figure 3, the whole sequence contains two sessions: one for the equilibrium concept and another one for the stability concept. Those two teaching sessions are based on the same architecture; we only detail the first one. There are four steps, two individual ones (1 and 3) and two collective ones (2 and 4). During the individual steps students are asked to state the equilibrium of various systems, in order to engage them into a personal active reflexion, and during the collective ones, they have to confront their opinions about those systems in order to construct a definition of the studied concept; this is the socio-constructivist (Doise \& Mugny, 1981) part of the learning situation. 
Accepted for publication in European Journal of Engineering Education, 2016 : http://dx.doi.org/10.1080/03043797.2016.1190689

\section{A priori analysis}

As said before, our choice is to put students in a situation in which they could be presented with various kinds of equilibrium. More precisely, here, students are asked to define the concept of equilibrium from the study of three systems: an equal arm balance, a human body and a pendulum-on-a-cart (see Canu, 2015, for more explanations about the two first systems and Canu et al., 2014 for the third): it is a definition problem. To promote the expected conceptual change, we chose to use a socio-cognitive conflict approach (Vygotsky, 1978; Ausubel, 1968, Doise \& Mugny, 1981) which implies small student-group work. This approach involves promoting a mismatch - the conflict between students' forecasts or ideas, and facts. One expects individual conflict (intrapersonal) as well as collective one (inter-personal).

In order to start the first cognitive conflict, students have to analyse individually two equilibrium balance cases and two equilibrium body cases (table. 1). Then, they are asked to say, individually, if each case is an equilibrium case and why.

[Table 1. near here]

Results from previous studies suggest a variety of students' responses that are representative of particular misconceptions. For example, case 1 in general is considered as in equilibrium by a majority of students. On the contrary, for case 2 , half of the students consider that it is not an equilibrium case (this is the outward sign of the "equilibrium-stable" conception). Thus, these elements, collected a paper-and-pencil Multiple Choice Questions (MCQ), are observable behaviours directly linked to the initial students' rationales or conceptions. 
Accepted for publication in European Journal of Engineering Education, 2016 : http://dx.doi.org/10.1080/03043797.2016.1190689

So, the second step of the session is to leave students facing the correct answer: all cases are cases of equilibrium. Because of the mismatch between their forecasts and this fact - in other words, the reality - given by the professor and some of the students, the group debate should lead to a cognitive conflict in students' mind. For this, some students with erroneous conceptions about the given concept are expected in each group. However, the prevalence of the pre-cited conceptions in the studied student population is sufficient to naturally fulfill this condition: a study we drove on 410 French and Colombian engineer students showed that $79 \%$ of them consider the equilibrium of a horizontal prototypic ${ }^{5}$ equal arm balance while only $22 \%$ consider it for an inclined prototypic equal arm balance.

During the group debate that follow, students have to find a first definition of equilibrium based on the study of those four cases and have to design an experiment that stems from it. This last exercise is directed at focusing them on equilibrium parameters like positions, disturbances, forces, etc. as well as time, in order to include those elements in their definition (for example, the identification of role of disturbances will help students to make a difference between equilibrium and stability). These two first steps will drive students to define equilibrium as a stationary state or, at least, as an "at rest" state, in agreement with the "equilibrium-immobility" conception. In order to infer this change in students' rational, we expressed a first didactical engineering hypothesis (DEH1) and the corresponding indicator (DEHI1) that links the observable behaviour of students and their rational. So, if students include the ideas of timeconstant state or variables and disturbance absence in their definition of equilibrium (this is the observable element DEIH1), then the construction of a stationary equilibrium conception from the study of these situations can be inferred (this is the hypothesis DEH1). This clues in a starting conceptual change. 
Accepted for publication in European Journal of Engineering Education, 2016 : http://dx.doi.org/10.1080/03043797.2016.1190689

The next two steps are designed to upgrade the previous definition in order to take motion into consideration. In particular, students have to discuss the role of frames of reference that is directly linked to the definition of the system limits: for example, which force is internal or external? Indeed, a previous study (Canu el al, 2014) showed that in this case of moving frame of reference, students' equilibrium conception is strongly perturbed.

Those steps aim at clarifying the equilibrium conditions in relation to external effects like those of pseudo-forces (inertial forces). Like in the two previous steps, the first one is individual and implies the study of two others cases: a pendulum-on-a-cart (table 2) equilibrium situation compatible with a zero acceleration of the cart, and another one compatible with a non- zero acceleration.

[Table 2 near here]

Students are asked to judge the possibility of the equilibrium for both the pendulum and the cart compared to the cart frame and to the ground frame. Then, during the next final step, they have to discuss their responses in order to take into consideration the previous definition (which does not work as it is in those cases, so this will produce a cognitive conflict) and the other students' opinion in a broader definition.

\section{Experimentation}

Two rounds of this didactical engineering sequence took place during the academic year 2013-2014 within the control design course of a Colombian engineering faculty. 37 students participated in this experiment during the second semester of 2013 and 50 students during the first semester of 2014. The first session was audio-recorded in order 
Accepted for publication in European Journal of Engineering Education, 2016 : http://dx.doi.org/10.1080/03043797.2016.1190689

to analyse the students' arguments. Students were settled into 4 or 5 during the debates phases.

Table 3 shows the results of the first individual multiple choice questionnaires (MCQ).

Only the first balance case (case 1) and the "man case" (case 4) led to unanimous answers. However, even in the case of a correct answer, some students provided incorrect or approximate arguments. For example, in the second case, a student can answer "yes", using the following argument "There is no external force troubling its natural state $[\ldots]$ " while the weight and the fulcrum reaction on the arm are indeed external forces.

In fact, quantitative results are only indicative ones, and were used only to record the heterogeneity of answers. The most important elements come from justifications we are going to analyse in the a posteriori phase.

[Table 3 near here]

\section{A posteriori analysis}

The main objective of this analysis is to verify (indirectly) the hypothesis of the a priori analysis (called DEH). For that, the "real" students" behaviour must be confronted with the expected one. The indications for students' behaviour come from the audiotranscription of the debates and the writings provided by all the multiple choice questionnaires (the justification parts). Roughly, the writings provide the activity's results (intermediate or final definitions) and the audio-transcriptions offer elements that explain how those results were produced, and the way students followed during the debates. So, for each important element in the definition (stationary condition, time, disturbances, system limits, etc.) we can verify its construction: moment of appearance, justification, discussion, etc. 
Accepted for publication in European Journal of Engineering Education, 2016 : http://dx.doi.org/10.1080/03043797.2016.1190689

As an example, figure 4 shows a short sparring match (verbal exchanges) between four students about the effect of disturbances in the "body" systems. In this excerpt, they discuss the role of disturbances, and more particularly the behaviour of the system when faced with such an action from outside the system. In the case of the human body (person), it is clear for them that an action from the wind or another person is a disturbance and this kind of argument comes more directly than in the balance case. For example, some of the students argued: "if there is a change in the environment that acts on the woman, she is going to fall". The equilibrium state of the system is a fact at this point for the students. So they can only discuss the definition of this concept and notice that while the balance and the body react differently to an external disturbance, they still are in equilibrium. This is a first step which drives them to the correct distinction between equilibrium and stability concepts. For example, at the end of the excerpt (verbal exchange), one student suggests that studying the system in the absence of external action changes could be enough. This is one of the expected arguments or indicator (DEHI1) that account for the verification of the DEH1 hypothesis expressed in the $a$ priori analysis.

Nota: We can see here that the role of "internal forces" is not very clear in students' mind. In fact, unlike the balance one, the "body" is a controlled system and the torque that acts on the foot is not only an "internal force" effect. The equilibrium body cases were chosen for this reason too: some studies (Newcomer and Steif, 2008, for example) report that students find it difficult to identify external and internal forces in a system. We can infer that these difficulties come from a failure in the system definition - limits - and this example is appropriate for questioning this points. This specificity have been discussed by students in the stability sequence. 
Accepted for publication in European Journal of Engineering Education, 2016 : http://dx.doi.org/10.1080/03043797.2016.1190689

[Figure 4 near here]

\section{Results}

In the Didactical Engineering methodological frame, results appear in the confrontation between the a posteriori analysis and the a priori analysis. Students' statements (audio and written) show that they were able to define the equilibrium concept taking into account the role of time (the stationary aspect), the disturbances (their definition and their effect on the studied system), and the definition of the system limits (that include the choice of the variables to take into account in the analysis). Finally, most of the group gave a definition in agreement with the expected elements like: "A system is in equilibrium if the variable(s) of interest do(es) not change over time, assuming that the disturbances remain constant". This is one of the expected indicators of the first session goals achievement and, in comparison to the initial students' arguments and conceptions; one can thus infer a beginning of conceptual change during the session.

\section{Discussion}

The efficiency of the sequence relies on the construction of a proper - i.e. a scientific definition of the equilibrium concept (and then of stability) by the students themselves. In order to reach this objective, students must use their previous conceptions about the given concepts and compare them to the opinion of their peers and to the expected behaviour of some well-chosen systems, in order to construct their own understanding. The a priori vs. a posteriori analysis shows that students' arguments during debates and their writings (intermediate and final ones), which are observable behaviours; allow us to infer the construction of the expected knowledge. Remember that in this kind of activity, no new elements of knowledge are offered by the professor during the activity. 
Accepted for publication in European Journal of Engineering Education, 2016 : http://dx.doi.org/10.1080/03043797.2016.1190689

In fact, in our case, students have (globally) all the required elements of knowledge in order to resolve this definition problem. Thus, the expected conceptual change here is "only" a rearrangement of this previous knowledge in the sense of a scheme modification (in fact, new action rules in the conceptual fields theory) involving a more scientific and coherent reasoning. However, this does not mean that it is an easy task. In fact, as shown by statistical data collected in the final exam of the course where this activity took place, we could only consider that the sequence started the conceptual change but this effect should be confirmed. More precisely, the extension of the equilibrium concept from these cases or situations to another domain or any equilibrium situation is not guaranteed even if we have some elements in this way (results from a final examination). This point should be deeply investigated in other study and it is important to note that this is not specifically due to the methodology limits but to the nature of the learning objective. In fact, although Didactical Engineering is mainly a research method, it can be used as a learning activity design method with some precautions that are presented in Artigue et al. (1991, 2009). More precisely, the presented learning sequence can be seen as a micro-engineering sequence as it deals with short time activities (1h20) and sequence ( 2 times), well-delimited concepts. Moreover, the teacher intervention is restricted to the minimum. In this case, it can be claimed that the distance between the research product and the action product (Artigue, 1991, p.14) could be considered as very small. Additionally, the implementation of this sequence was included in a typical - said, classical - control course and design to be part of it, in order to ensure correct reproducibility and stability.

\section{Conclusion}

This study shows that it is possible to reach a significant effect in students' understanding of physical or engineering concept using an adequate sequence design 
Accepted for publication in European Journal of Engineering Education, 2016 : http://dx.doi.org/10.1080/03043797.2016.1190689

with the Didactical Engineering methodology, even in case of deeply rooted misconceptions like in the equilibrium case. This methodology could be supported by various theoretical frameworks according to the specific desired learning effect. In our case, a psycho-cognitive approach allowed us to design a sequence that promotes a conceptual change which consists in a unification of various alternatives conceptions. The proposed sequence implies a strong teacher commitment in order to guide students' work during the sessions but without direct "provision of knowledge" in agreement with its constructivist bases. In fact, each session entails also a real student commitment and as many others active learning strategies, this only can work properly with a low teacher/students number ratio.

\section{References}

Albanese, A., Cesar, M., Neves, D., \& Vicentini, M. (1998). Students' ideas about equilibrium, friction and dissipation. Acta Scientarium, 20(4), 461-472.

Artigue, M., \& Perrin-Glorian, J. (1991). Didactic Engineering, Research and Development Tool: Some Theoretical Problems Linked to This Duality. For the Learning of Mathematics, 11(1), 13-18.

Artigue, M. (1994). Didactical engineering as a framework for the conception of teaching products. In R. Biehler, R. W. Scholz, R. Sträßber, \& B. Winkelmann (Eds.), Didactics of mathematics as a scientific discipline (Mathematic., Vol. 54, p. 481). Dordrecht: Kluwer Academic Plublishers. doi:10.1007/0-306-47204-X Artigue, M. (2009). Didactical design in mathematics education. In C. Winslow (Ed.), Nordic research in mathematics education. Proceedings from NORMA08, Copenhagen, 21-25 Apr 2008 (pp. 7-16). London: Sense.

Ausubel, D. P. (1969). A cognitive theory of school learning. Psychology in the Schools, 6(4), 331-335. 
Accepted for publication in European Journal of Engineering Education, 2016 : http://dx.doi.org/10.1080/03043797.2016.1190689

Bonawitz, E. B., Lim, S., \& Schulz, L. E. (2007). Weighing the evidence : Children's naïve theories of balance affect their exploratory play. In 28th Annual Proceedings of the Cognitive Science Society. Nashville, Tennessee: Lawrence Erlbaum Associates.

Brousseau, G. (1988). Le contrat didactique: le milieu. Recherches En Didactique Des Mathématiques, 9(3), 309-336.

Brousseau, G. (1997). Theory of didactical situation in mathematics. (N. Balacheff, M. Cooper, R. Sutherland, \& V. Warfield, Eds.). Dordrecht,The Netherlands: Kluwer Academic Publishers.

Canu, M. (2015). Apport de l'étude conjointe de systèmes libres et commandés dans la compréhension des concepts d'équilibre et de stabilité. IREM de Paris. ISBN : 978-2-86612-358-1. https://hal.archives-ouvertes.fr/tel-01108459

Canu, M., de Hosson, C., \& Duque, M. (2014). STUDENTS' UNDERSTANDING OF EQUILIBRIUM AND STABILITY: THE CASE OF DYNAMIC SYSTEMS. International Journal of Science and Mathematics Education, (on-line first edition). doi:10.1007/s10763-014-9565-6

Canu, M. \& Duque, M. (2014). Didactic engineering for conceptual change in students' equilibrium and stability understanding. Active Learning in Engineering Education - Caxias du Sul, 20-22th of January 2014, 292-299.

Chi, M. T. H. (2009). Active-Constructive-Interactive: A Conceptual Framework for Differentiating Learning Activities. Topics in Cognitive Science, 1(1), 73-105. doi:10.1111/j.1756-8765.2008.01005.x

diSessa, A. A. (1993). Towards an epistemology of physics. Cognition and Instruction, $10(2-3), 105-225$.

diSessa, A. A., Gillespie, N., \& Esterly, J. (2004). Coherence versus fragmentation in 
Accepted for publication in European Journal of Engineering Education, 2016 : http://dx.doi.org/10.1080/03043797.2016.1190689

the development of the concept of force. Cognitive Science, 28(6), 843-900. doi:10.1016/j.cogsci.2004.05.003

Doise, W., \& Mugny, G. (1981). Le développement social de l'intelligence (IntereEdit.). Paris.

Gunstone, R. F. (1987). Student understanding in mechanics: A large population survey. American Journal of Physics, 55(8), 691-696.

Newcomer, L. J., \& Steif, S. P. (2008). Student Thinking about Static Equilibrium: Insights from Written Explanations to a Concept Question. Journal of Engineering Education, 481- 490.

Flores-García, S., Alfaro-Avena, L. L., Chávez-Pierce, J. E., Luna-González, J., \& González-Quezada, M. D. (2010). Students' difficulties with tension in massless strings. American Journal of Physics, 78(12), 1412.

Minstrell, J. (1992). Facets of students' knowledge and relevant instruction. In R. Duit, F. Goldberg, \& H. Niedderer (Eds.), Research in physics learning: Theoretical issues and empirical studies (pp. 110-128). Kiel: IPN.

Ortiz, L.G., Heron, P. R. L., \& Shaffer, P. S. (2005). Student understanding of static equilibrium: Predicting and accounting for balancing. American Journal of Physics, 73 (6), 545.

Palmer, D. H. (2001). Investigating the Relationship Between Students' Multiple Conceptions of Action and Reaction in Cases of Static Equilibrium. Research in Science and Technical Education, 19(2).

Piaget, J. (1950). The psychology of intelligence (p. 192). London: Routledge \& Kegan Paul.

Pozo, J. I., del Puy Pérez, M., Sanz, A., \& Limón, M. (1992). Las ideas de los alumnos sobre la ciencia como teorías implícitas. Infancia Y Aprendizaje, (57), 3-22. 
Accepted for publication in European Journal of Engineering Education, 2016 : http://dx.doi.org/10.1080/03043797.2016.1190689

doi:10.1080/02103702.1992.10822321

Prince, M. (2004). Does Active Learning Work ? A Review of the Research. Journal of Engineering Education, 93(3), 223-231.

Siegler, R. S., \& Chen, Z. (2002). Development of rules and strategies: balancing the old and the new. Journal of Experimental Child Psychology, 81(4), 446-57. doi:10.1006/jecp.2002.2666

Tamayo, F. J., Canu, M., \& Duque, M. (2012). Didactic engineering applied to control system learning : equilibrium and stability concepts in the ball and beam experiment. In C. C. M. Spliid, P. H. Andersson, \& Jørgen B. Røn (Eds.), Active Learning in Engineering Education. Copenhagen, Denmark.

Vergnaud, G. (2009). The theory of conceptual fields. Human Development, 52, 83-94. doi:10.1159/000202727

Viennot, L. (1979). Spontaneous Reasoning in Elementary Dynamics. European Journal of Science Education, 1(2), 205-221. doi:10.1080/0140528790010209

Vos, H., \& de Graaff, E. (2004). Developing metacognition: a basis for active learning. European Journal of Engineering Education, 29(4), 543-548. doi:10.1080/03043790410001716257

Vygotsky, L. (1978). Interaction between learning and development. Mind and Society (pp. 79-91). Cambridge, Mass.: Harvard University Press. 
Accepted for publication in European Journal of Engineering Education, 2016 :

http://dx.doi.org/10.1080/03043797.2016.1190689

\section{List of figures (captions):}

Figure 1: The initial conceptual field.

Figure 2: The final conceptual field.

Figure 3: The proposed classroom sequence.

Figure 4: A group debate excerpt (with one color per student).

\section{List of tables (captions):}

Table 1: Equal-arm balance and body equilibrium cases (extracted from Canu, 2015).

Table 2: Pendulum-on-a-cart equilibrium cases (extracted from Canu, 2015).

Table 3: Answers to the first individual MCQ during the first session ( $\mathrm{n}=37)$.

i For more mathematical details, see for example Åström, K. J., \& Murray, R. M. (2009). Feedback Systems: An Introduction for Scientists and Engineers. Control And Cybernetics (Vol. 36, p. 426). Princeton University Press.

ii Clearly this is not the logical negative form of the rule. Since the rule is, in fact, a logical implication ("at rest" implies "equilibrium"), the negation of the antecedent ("moving") does not implies the negation of the consequent (non-equilibrium). 
Accepted for publication in European Journal of Engineering Education, 2016 : http://dx.doi.org/10.1080/03043797.2016.1190689

iii Bonwell, C.C., and J. A. Eison, "Active Learning: Creating Excitement in the

Classroom,” ASHEERIC Higher Education Report No.1, George Washington

University, Washington, DC, 1991.

iv For more details about this notion of milieu, which is more than a simple social environment, read Brousseau (1988) La théorie des situations didactiques, La pensée Sauvage, pp. 115-160, Grenoble. 